\title{
Developing Library GIS Services for Humanities and Social Science: An Action Research Approach
}

\author{
Ningning Kong, Michael Fosmire, and Benjamin \\ Dewayne Branch*
}

\begin{abstract}
In the academic libraries' efforts to support digital humanities and social science, GIS service plays an important role. However, there is no general service model existing about how libraries can develop GIS services to best engage with digital humanities and social science. In this study, we adopted the action research method to develop and improve our service model. Our results suggested that a library's GIS service can support humanities and social science from the research collaboration, learning support, and outreach perspectives, with different focuses according to the stages of learning and research. The research framework adopted in this study not only can serve as an efficient tool for developing GIS services but also can be expanded to other library service areas.
\end{abstract}

\section{Introduction}

Geographic Information Systems (GIS) services began to be offered by research libraries in the early 1990s and has been evolving in the past twenty years to accommodate the rapid growth of geospatial information in multiple disciplines. ${ }^{1}$ In the ARL's effort to emphasize the library's role in supporting digital humanities and social science, ${ }^{2}$ GIS can play an important part. In the "spatial turn" movement of these disciplines, which refers to the movement of emphasizing places where human actions occur, GIS has been an influential tool and generated massive amounts of research in the past two decades. ${ }^{3}$ GIS can help to spatially conceptualize research topics, quantify social, cultural, and historical information, and analyze the data in new ways. ${ }^{4}$ However, barriers exist for the humanities and social science scholars to use GIS, which prevent most of them from really adopting the "spatial turn" in their research. These barriers include spatial literacy, technical skills, system requirements, and data collection and handling. ${ }^{5}$

As the centralized place to provide geospatial support on campus, libraries' GIS service can play an active role in assisting scholars in these disciplines, so that most of the barriers can be overcome. ${ }^{6}$ To establish efficient GIS services in libraries to address these issues requires a thorough understanding of each campus's specific needs due to

\footnotetext{
*Ningning Kong is Assistant Professor, GIS Specialist at Purdue University Libraries, e-mail: kongn@ purdue.edu; Michael Fosmire is Professor of Library Science and Head, Physical Sciences, Engineering, and Technology Division at Purdue University Libraries, e-mail: fosmire@purdue.edu; Benjamin Dewayne Branch is CLIR/DLF Data Curation Post-doctoral Fellow at Purdue University Libraries, e-mail: bdbranch@ gmail.com. (02017 Ningning Kong, Michael Fosmire, and Benjamin Dewayne Branch, AttributionNonCommercial (http://creativecommons.org/licenses/by-nc/4.0/) CC BY-NC.
} 
different departmental settings, user groups, available resources, and history of GIS in library. ${ }^{7}$ Many studies have discussed the complexity of implementing a GIS service, yet very few discussions have focused on how the service model has been developed to fit campus needs. ${ }^{8}$ In this study, we adopted and modified the action research model to study the humanities and social science's GIS needs on our campus. In this model, we started from user interviews, then analyzed the collected information with NVivo, designed services according to the analysis, and observed the outcomes from the designed services. All the experiences from our practice and observation steps, in turn, contribute back to the information collection pool, which will help us to enhance future services. The research framework adopted in this study provides a guideline for libraries to establish their GIS programs for humanities and social science, or other subject areas. In addition, this framework can be expanded to other library service areas, such as data services and special collection services, in establishing their own campus-specific programs.

\section{Literature Review}

In the early years that GIS services appeared in the libraries, there were three major roles that the services provided: collection development, spatial information access, and spatial literacy. ${ }^{9}$ These service areas have evolved in the past two decades as academic libraries' services developed and GIS technology advanced. Traditionally, research libraries collected and provided access to raw GIS datasets, such as census materials and digital maps, which can only be used by professional GIS users with specialized software. As the web-based mapping technology developed in recent years, libraries began to subscribe to databases with web map interfaces, such as SimplyMap, PolicyMap, and Social Explorer. ${ }^{10}$ These databases provide easy access to spatial information for users without a GIS background. Thus, humanities and social science researchers can access external spatial information without as many technology barriers.

To promote spatial literacy, many studies found that libraries can and often do play a strong and influential role in the use of GIS on campuses. ${ }^{11}$ Librarians have tried different approaches to engage campus users, including consultations, workshops, and classroom visits. ${ }^{12}$ Some studies found that classroom instruction is an effective means of introducing GIS to new users, ${ }^{13}$ while other studies suggested that the efficient way of introducing GIS is to establish a geospatial workshop program that offers presentations and hands-on exercises outside classroom time. ${ }^{14}$ Therefore, understanding campus needs is critical in establishing a GIS learning program, especially in humanities and social science disciplines at our institution, where GIS has not been well supported.

In recent years, research data management and curation has become an emerging library service, which can easily be added to traditional GIS services. Especially in humanities and social science, librarians are increasingly supporting researchers to gather original data, organize and manage data, create visualizations, and share their scholarship through various publication formats. ${ }^{15}$ In the discussion of data services, there are two directions of service that are often referred as "upstream" and "downstream" services. ${ }^{16}$ Since the data lifecycle begins early in the scientific process, new data services can be developed "upstream," before and while data is first collected. Also, there are opportunities for libraries "downstream" in postproduction and postpublication stages. This statement is applicable for GIS services in humanities and social science. In the upstream, GIS librarians and related researchers need to work closely to identify the geospatial data characteristics in these areas and explore optimal strategies in meeting the users' expectations. In the downstream, GIS data services can be developed around spatial data organization, metadata creation, online spatial data visualization, or data dissemination via a spatial data portal. Librarians need to understand the researcher's data publication expectations and constraints to provide appropriate service. 
In addition to the services mentioned above, outreach is another frequently discussed topic in GIS. ${ }^{17}$ Since GIS is a relatively new and still evolving service area in libraries, making patrons aware of it is essential. Moreover, GIS is an emerging technology in many disciplines. Introducing the concept to researchers is critical for them to adopt it in their studies. Many academic libraries have found that GIS Day is an excellent opportunity to highlight GIS applications across disciplines, raise awareness of library GIS services, and make connections. ${ }^{18}$

Previous literature not only describes library GIS services by scope, but also by depth of service. ${ }^{19}$ The first level of GIS service was described as serving users with little experience, where a basic mapping tool is introduced. The second level of GIS service targets users with some experience, where spatial data manipulation, query, and customization are introduced. And the third level is for proficient users needing assistance with data capture, storage, and information analysis. Accordingly, the required GIS librarian skills have been defined by the ALA Map and Geography Round Table at these three different levels. ${ }^{20}$ In humanities and social science, users exist in all these three levels. The challenge is to build the best mixture of all levels of services.

\section{Research Framework and Results}

By reviewing previous studies and practices, it has become obvious that understanding campus needs in addition to discipline-specific needs is critical to provide appropriate services. In this study, we built our research framework on a modification of the action research model and used the Data Curation Profiles (DCP) toolkit ${ }^{21}$ to learn about campus needs and to build our specific service model. Action research is an interactive research process that balances problem-solving actions with data-driven analysis to solve a particular problem and to produce guidelines for best practices. $^{22}$ Action research theory was first developed by Kurt Lewin in industrial and organizational settings ${ }^{23}$ and later taken up in educational research. With almost seven decades of development, many methods have evolved that adjust the approach to focus on selected research areas. $^{24}$

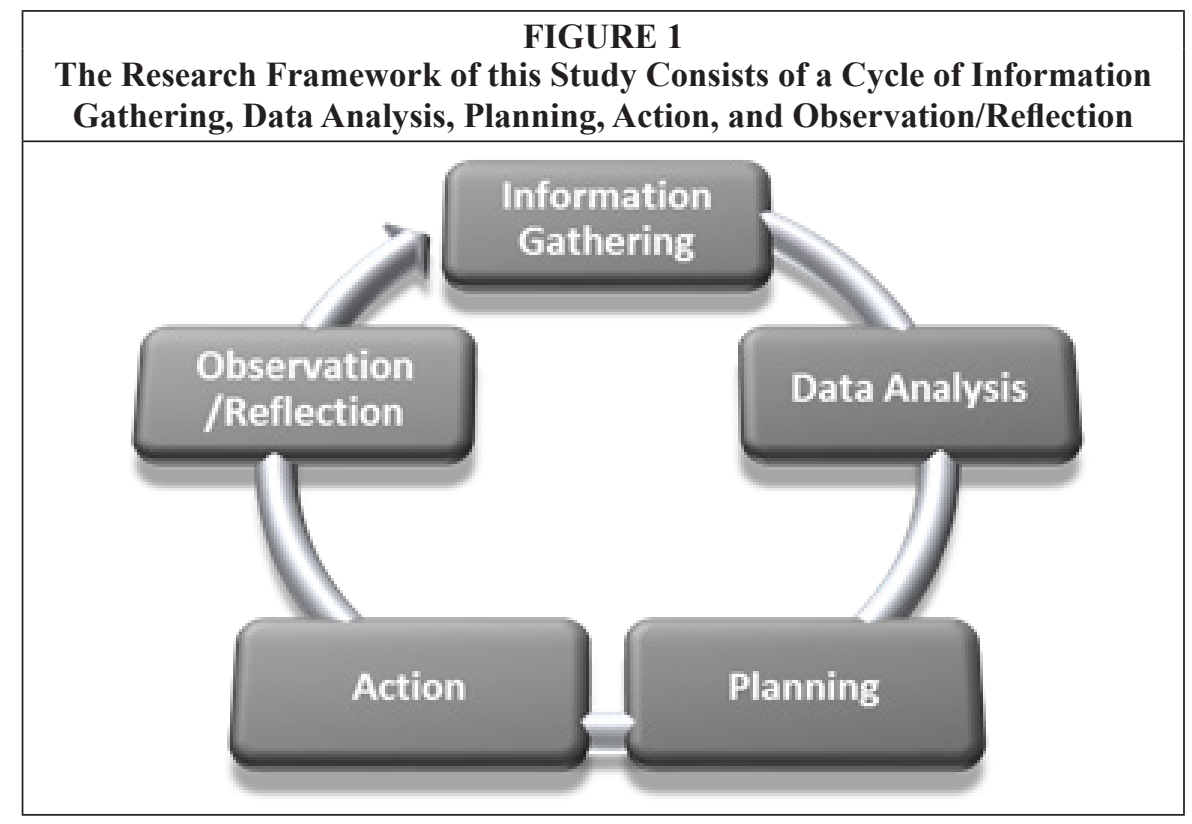


With the goal of designing and improving library GIS services for humanities and social science, we modified the original action research framework to fit our needs, as depicted in figure 1. To understand our campus and discipline-specific needs, we emphasized the background information collection and data analysis stages. We started by interviewing faculty and graduate students, identifying their expectations from the interview data. Based on the analysis, we made our action plans. The observations and evaluations during our practices provide feedback into the information-gathering stage to improve our future planning and practices. In the long term, the research framework, taking into account the users' expectations and practical experiences, can help us to improve the quality of library services. In the following paragraphs, we will introduce the details of our method and research results in each of the five stages.

\section{Information Gathering}

To learn about the campus and disciplinary needs, we modified the Data Curation Profiles (DCP) for our research purpose. DCP is designed to capture data requirements from researchers, which enable librarians to make informed decisions in developing data services, as well as identifying the tools, infrastructure, and responsibilities for those services. ${ }^{25}$ There are two reasons that DCP was used for this research. First, DCP offers a structure of inclusive interview questions with flexibility to be extended in any domain or discipline. Second, data is an excellent starting point to initiate conversations between librarians and researchers in learning the discipline's research and teaching expectations. A general data lifecycle involves raw data collection, processing, analysis, and publication. ${ }^{26}$ By learning the characteristics and tools through these different stages of the data lifecycle, librarians can understand the information needs and data management and learning expectations of the researchers.

Our modified DCP interview includes eight modules with questions related to GIS applications and data management in research projects (see table 1). It includes openended and multiple-choice questions, as well as other questions emerging from the dialogue. It typically took about 90 minutes to complete one interview.

To identify potential interviewees, we first contacted faculty who had requested GIS help from our library. From that group, we gathered referrals to other faculty who used or had a potential to use GIS in their research. We also interviewed graduate students of faculty who didn't use GIS themselves but supervised students using GIS. In total, we conducted 8 interviews, including 4 faculty, 3 graduate students, and 1 research group of faculty and graduate students. The interviewees came from five departments in College of Liberal Arts, and the faculty population includes a combination of early-career, midcareer, and well-established professors. We limited our population to 8 interviews because 1 ) on our campus GIS is still an emerging topic in humanities and social science with a limited number of users; and 2) themes started repeating frequently, which indicated a saturation point in data collection.

In addition to the DCP semistructured interviews, we included in our analysis the meeting notes with various students who visited our library for GIS help and unofficial e-mail feedback from GIS users who shared their expectations with the libraries. All these data were organized in NVivo for further analysis.

\section{Data Analysis}

Grounded theory has proven to be an effective way to analyze qualitative interviews and observation notes. ${ }^{27}$ Grounded theory is defined as a method that develops a theory by inductively analyzing and conceptualizing a corpus of data. ${ }^{28}$ In recent years, with the development of computer-aided qualitative data analysis software, many studies have suggested the software, such as NVivo, can be used successfully to facilitate a grounded theory investigation. ${ }^{29}$ 


\begin{tabular}{|c|c|}
\hline \multicolumn{2}{|c|}{$\begin{array}{c}\text { TABLE } 1 \\
\text { Interview Modules with Expected Outcomes }\end{array}$} \\
\hline Interview Modules & Outcome \\
\hline 1. Project and Datasets & $\begin{array}{l}\text { Learn about researcher's lab, research interests, GIS } \\
\text { linkages in the projects, data sources, and so on. }\end{array}$ \\
\hline 2. Lifecycle of the Dataset & $\begin{array}{l}\text { Learn about the project workflow and research method to } \\
\text { identify possible service areas and frequently used tools. }\end{array}$ \\
\hline 3. Critical Skills for Students & $\begin{array}{l}\text { Identify the critical GIS and data skills that are important } \\
\text { for students in the discipline. }\end{array}$ \\
\hline 4. External Information & $\begin{array}{l}\text { Learn about frequently used databases, necessary skills to } \\
\text { acquire data. }\end{array}$ \\
\hline 5. Tools & $\begin{array}{l}\text { Learn about GIS and data handling software/hardware in } \\
\text { the project. }\end{array}$ \\
\hline 6. Data Sharing and Access & $\begin{array}{l}\text { Learn about data sharing and access expectations and } \\
\text { constraints. }\end{array}$ \\
\hline $\begin{array}{l}\text { 7. Data Organization, } \\
\text { Description and Management }\end{array}$ & $\begin{array}{l}\text { Learn current status of data management strategies and } \\
\text { discuss possible improvements. }\end{array}$ \\
\hline 8. Expected GIS Services & $\begin{array}{l}\text { Discuss other expected GIS services that were not } \\
\text { discussed in previous questions. }\end{array}$ \\
\hline
\end{tabular}

Developing the user expectation metrics from our collected data involved several iterations of data collection, coding, and analysis. First, the data were imported into NVivo with attributes, which recorded descriptive information about each interview (such as department, faculty vs. student status, and data source). Then, in the open coding stage, we attached meaningful code to data segments to identify preliminary concepts and then organized the same code into nodes. In the next stage, we categorized the initial nodes and created a node structure based on the generated categories. Finally, we developed the concepts based on the categories, attribute information, and axial coding (relating categories to their subcategories). From our analysis, we found user expectations for GIS services fell into three themes: research, learning, and outreach (see figure 2).

FIGURE 2

GIS Service Expectation Metrics Generated from the Collected Information

Research
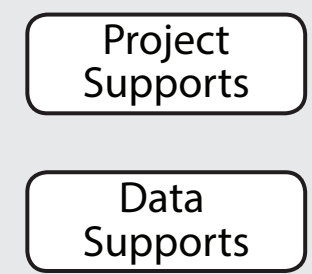

Learning Spatial Skills

Data Skills

Tool Skills
Outreach

Spatial Awareness

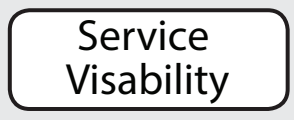




\subsection{Research Support Expectations}

We identified a common project workflow from our interviews and mapped the research support expectations to the workflow (see left side of figure 3). In the initial planning stage, researchers expect to get support to brainstorm ideas for spatial information integration and design related research methods and outcomes. Since using spatial information is a relatively new direction in humanities and social science, researchers are interested in finding examples of existing projects or potential spatial analysis methods they can deploy. They are also interested in knowing available spatial information and resources, as well as platforms they can use to share their data and publications.

In the data collection stage, interviewees faced two major challenges: first, collecting historic spatial information that changes over time; second, difficulties integrating data collected by different collaborators without a predesigned data collection schema. Based on this feedback, the library could collaborate with researchers in the early project development stage to plan and design data collection strategies.

In the data processing and organization stage, researchers integrated, cross-checked, and organized their data into tables or databases. Interviewees indicated that the most frequently used software, such as Excel, cannot capture the relationships between datasets. Thus, they lost some important information and decreased the possibility for cross-validation. These data relationships are especially important for humanities and social sciences. For example, researchers in these disciplines are more interested to know the collaborations between book authors, the coexhibitions between artists, and the letters between historic characters. They felt it would be ideal if the library could work with the project team to design a more sophisticated database to store the information and design strategies to validate collected information. In addition, many researchers welcomed suggestions or tools to help manage their dataset, such as effective file structure and naming conventions, a reliable space for collaboration and backup, and an efficient version control strategy.

Data analysis was described as the most complicated part in the project workflow. The humanities and social science researchers formed two very distinct groups in this stage. Humanists focused on the description of data itself (including both statistical characteristics and qualitative descriptions), and the spatial distribution pattern of their data. Social scientists were more interested in understanding the spatial analysis capabilities of GIS, especially to answer the spatial-temporal questions raised in their research. Both the spatial visualization needed in humanities and the spatial-temporal analysis needed in social sciences are not the teaching focuses in our existing campus GIS courses. The interviewees suggested that the library could either provide learning modules or collaborate directly in the research to make their projects truly spatial.

In the final stage, publication and data sharing, humanities and social science researchers also have different expectations in their spatial outcomes. Humanities researchers often expected to share their data through a user-friendly web map that has the capability for users to add comments. Social scientists in this study did not express enthusiasm to share their data, although they were willing to share with some constraints after their related articles were published. The constraints included requiring a full understanding of the dataset, data citation with acknowledgement, and data exchange between colleagues.

\subsection{Learning Support Expectations}

Our analysis identified three basic categories of skills that are critical for humanities and social science researchers to be able to use geospatial information effectively. These three categories are spatial thinking skills, data skills, and tool skills. As the campus pioneers of using GIS in humanities and social science, our interviewees believe that the 
most significant barrier for students using GIS in their disciplines are spatial thinking skills. Typical GIS instruction introduces concepts from environmental studies or civil engineering perspectives, which have well-organized quantitative data sources. This approach does not align well with the time-sensitive and qualitative data in humanities and social science. Interviewees believed that there should be more introductory-level learning opportunities on campus, which will inspire the larger community to think about spatial integration from their project-planning stage. For example, what is GIS? What will be possible if GIS is applied in the humanities and social science? What are the resources available to learn and use GIS? As more people start to think spatially, the library can provide more in-depth resources to introduce specific spatial analysis functions, web GIS possibilities, and mobile GIS solutions.

Humanities and social science researchers considered data skills most important when integrating their disciplinary information into a spatial format. For example, how to collect and organize historic GIS data, how to deal with data in different formats, how to clean up data, and how to integrate disciplinary data with geospatial information. Another area of data skills is about external data sources. Researchers are interested to train the students in these disciplines about available GIS data, digitizing historic materials, information-access methods, and the ability to evaluate the quality of external data.

The next set of skills students need to be able to use geospatial information effectively is using the tools: that is, how to use the related software and hardware. Our interviewees used both GIS tools and data tools. GIS tools included ArcGIS, Google Earth, some web GIS APIs (such as Google Map and OpenLayers), and GPS devices. The interviewees stated that they had to learn those tools on their own. Data tools included Excel, Access, geodatabases, and enterprise databases. Interviewees already had some background knowledge about these tools but still desired to learn more specific skills in data handling. In addition, they used other software/hardware such as statistical packages, audio recording devices, and Wordpress, which they had already learned in their disciplinary methodology courses. It has become clear that the campus training gap in terms of using geospatial tools is using GIS-specific software/hardware for these disciplines and some specific data-manipulation skills.

In addition to learning content, many researchers have expressed their concerns about the format of learning. Spatial concepts are a relatively new area for students in these disciplines. They believed that learning can only be effective if the learning resources can be provided in a way relevant to the students' disciplines and research interests.

\subsection{Outreach Expectations}

Outreach expectations were mentioned by our interviewees, even though it was not initially designed into our interview questions. The researchers expect the library's GIS services to reach out in two major areas: increasing the awareness of spatial information and technology campuswide and increasing the visibility of GIS services in the library. Increasing the awareness of spatial information aligns with the learning expectation of improving spatial thinking skills. The interviewees believed that, with more people being aware of spatial concepts, the library can have more users of GIS services.

\section{Planning}

The user expectations generated from the data analysis stage served as guidelines for the planning stage. Within each user expectation area, we evaluated available library resources and designed activities to address those expectations. Prior examples from the literature of library supports in humanities and social science and GIS services were also important references in our planning stage. 


\subsection{Research Support Planning}

In the research collaboration planning stage, we designed our library services following the interviewees' general research process. GIS services can be built at each stage of the project workflow, from the early research development to data publication and sharing. The planned activities are summarized in the right side of figure 3 .

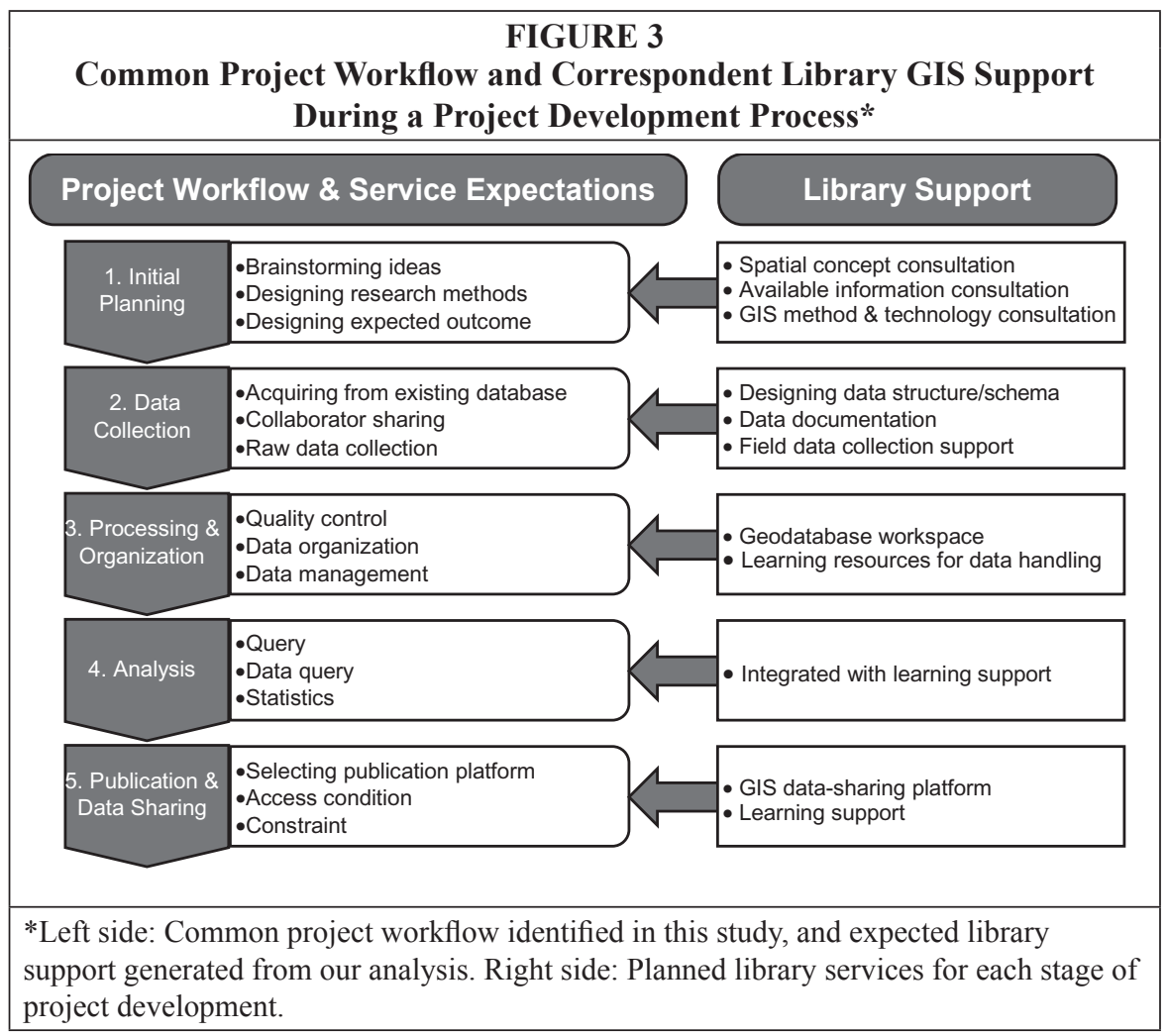

At the project initial planning stage, library support can be provided by consultations. GIS librarians can provide consultations in spatial concepts, available spatial information, GIS technology, and methodology. Conceptually, librarians can discuss and provide examples of the possibilities of using GIS in the proposed project. Technically, librarians can work with the patrons to identify appropriate technologies for the project and plan for acquiring skills needed to implement those technologies. Methodologically, librarians can work with the patrons to design specific geospatial data collection, visualization, management, and analysis methods during the project development. From a resource perspective, librarians can suggest available spatial databases that the patrons can use.

The expectation in the data collection stage has led us to organize potential data sources relevant to humanities and social sciences. For example, we have prepared instructions about integrating historical census data into GIS, using NHGIS database, georeferencing historic maps, and so on. To facilitate data organization, field data collection, and data publication needs, we worked with our library's Information Technology group to set up a GIS server environment, enterprise geodatabase, and prepare storage space to serve potential collaboration opportunities. To accommodate the data 
analysis expectation, we emphasized available learning resources and training plans for the students involved in the projects, instead of providing hands-on services. Because data analysis varies a lot in different projects, it is impossible to commit a librarian's time deeply into each project's data analysis.

\subsection{Learning Support Planning}

In the learning service planning stage, we designed the library services with reference to different levels of GIS services discussed in previous literature. ${ }^{30}$ A four-layer approach was planned for providing learning resources ( see figure 4). From beginners to specific interest groups, this approach includes providing online learning resources, classroom visits, workshops, and credit courses.

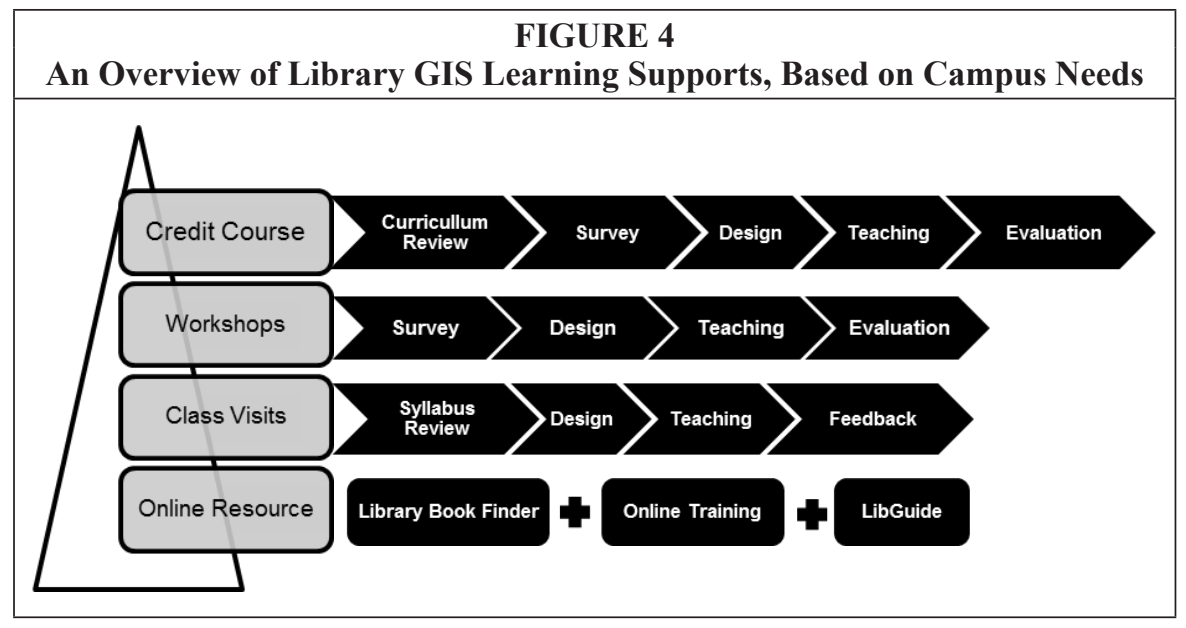

Online resources provide a starting point for students who are interested in learning GIS by teaching themselves. In addition to providing access to online learning modules, we also created a LibGuide to introduce GIS data resources and a book finder page to locate GIS books in the library by category and discipline. As most of the professors indicated that learning GIS must be integrated into their research subjects, we planned to visit classrooms where GIS is applicable. Workshops offer a flexible way to provide GIS learning opportunities for anyone who wants to learn GIS through hands-on experience. In the planning stage, we identified most relevant topics for the disciplines and organized teaching materials accordingly. These topics included an introduction to GIS, digitizing historic spatial information, and creating web story maps. In addition, our library also reached out to the College of Liberal Arts to offer a three-credit GIS course for students in humanities and social science.

\subsection{Outreach Planning}

In the outreach planning stage, we considered user expectations from our analysis and other GIS libraries' experiences to form a GIS Day planning committee, which includes faculty, staff, students, and outreach and marketing experts. The planning committee meets quarterly to brainstorm ideas, design and discuss activities, and review progress.

\section{Action and Observation}

With all the preparations, we made connections to a larger population to test our planning ideas and carry forward the action items. We collected information from users across 
the full action implementation stage. Depending on the nature of different services, we collected the background information before the service, took notes during the service, and conducted surveys/evaluations after the service to collect as much information as possible. All the information collected in this stage was imported into NVivo and will contribute to the next round of data analysis for future service improvement.

\subsection{Research Support Action and Observation}

To provide consultation in project planning stage, we redesigned our library GIS webpage to showcase sample projects we have worked on and provide convenient contact information for consultation. We also reached out to specific research groups to increase the awareness of GIS service. As a result, there have been about forty inperson consultations provided in our library at the planning stage of a project in the past two years. The majority of the visitors were graduate students who were about to start their dissertation research.

To address the data collection needs, we worked with the researchers at their early project development stage to design their data structures in a collaborative way. These data structure designs range from a single Excel template to a complicated relational database with both spatial and tabular information. In addition, we worked with the research team to design the data documentation strategies before the data collection was done, to document (for example) the file naming convention, column heading explanation, and data limitations. To support field data collection, we worked with researchers to create a mobile data collection solution to collect and manage their location-based field data.

As we have planned and prepared the enterprise geodatabase environment for researchers with data processing and management needs, we worked closely with researchers to design their database structures, including relationship classes and domain definitions, and lay out the design diagram. Then we built the database based on the design for each individual project. Based on our observation, although it required some learning curve for researchers in the beginning of their projects, the advantages of providing such a database space at the library include: (1) upscaling the separated data spreadsheets into a database with additional relationship information; (2) providing a centralized space for team-based collaboration, information sharing, and storage; (3) facilitating and synchronizing field data collection; and (4) data validation via built database rules. The challenge on the library side was storage space. Due to the nature of current humanities and social science projects on our campus, storage was not a big concern. For increasing storage demands in the future, we will either seek support at the budget planning stage of the proposal or refer the researcher to other public filesharing spaces, such as YouTube and Flickr, to host large video or image files.

In the analysis stage, we emphasized available learning resources and training plans for the students involved in the projects, instead of providing hands-on services. Exceptions occurred when the project was technology heavy and required more indepth knowledge in GIS. At the final stage of data sharing and publication, our library provided a GIS server to disseminate the project findings in an interactive map format. In addition, we offered training to students about how to build a web map so that they can customize their web representations on their own.

As a reflection of the impact of GIS services in humanities and social science research, the library has been included in two Andrew Mellon Foundation Grand Challenge awards and two National Endowment of Humanities (NEH) projects that were funded in the past two years; five humanities and social science projects were successfully moved to our library geodatabase; and thirty-nine map services in these disciplines have been published using our library's GIS server. 


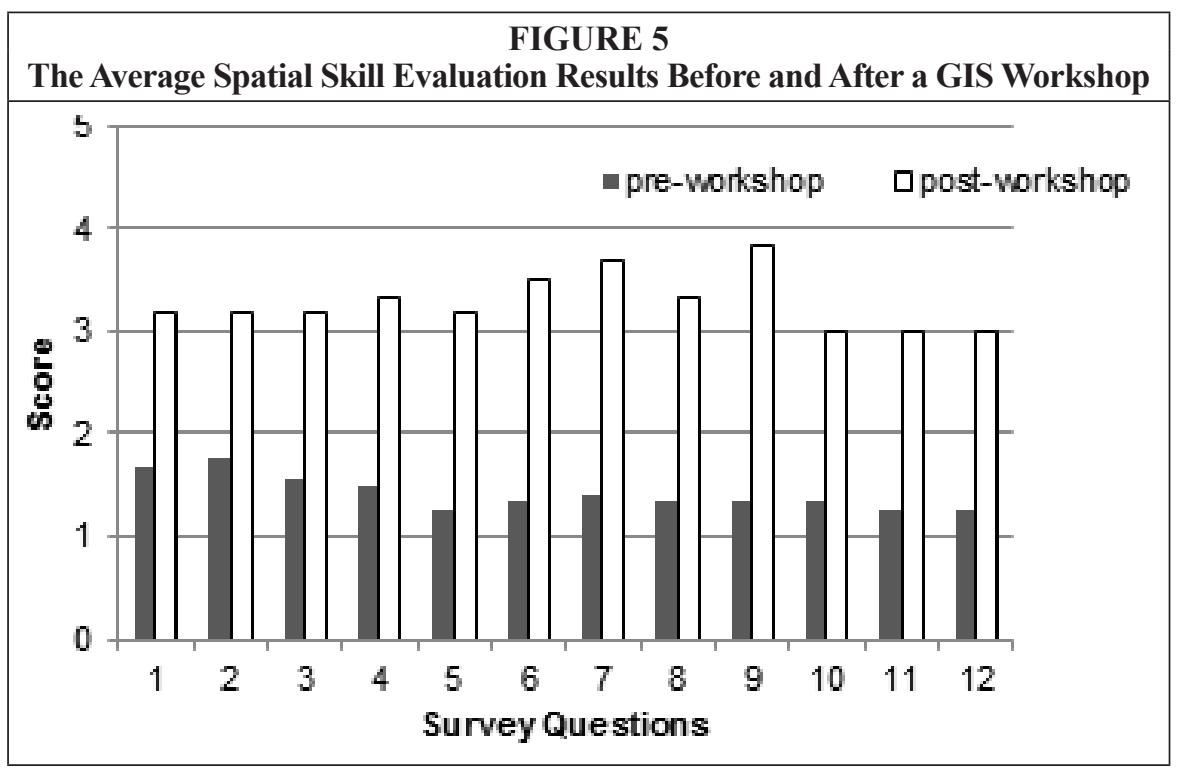

\subsection{Learning Support Action and Observation}

As for the four levels of learning support (see figure 5), we tracked the usage statistics for the first-level online learning resources. In the past year, there were 3,000 visits on our GIS service webpage, including 251 visits on workshop resources and 90 visits on library GIS book finder page.

At the second level, the librarian reached out to instructors in College of Liberal Arts who had applied different levels of spatial thinking skills in their own research and identified possible opportunities to introduce geospatial information into their classes. Before the visit, the librarian worked closely with the instructor to review the course syllabus, background information, and design scenarios about how GIS could be applied into their content area. During the teaching, we not only taught about the spatial thinking concept (spatial skill), but also provided hands-on experience to teach students how to use GIS tools (tools skill). We received feedback from all the visited classrooms that students were interested in learning more GIS and using it in their future research. We also observed that students from those classrooms began to visit the GIS library after the instruction was given.

To provide flexible GIS learning opportunities, we offered workshops on a variety of topics. During the workshops, we not only introduced spatial skills and hands-on tool skills, we also designed specific data challenges to teach some data handling skills. We offered Introduction to GIS workshops most frequently, in alignment with the uncovered learning needs. Furthermore, we worked with education experts to design surveys based on spatial thinking skill evaluation research. ${ }^{31}$ For the preworkshop survey, in addition to the spatial skill assessment questions, we also collected information about the students' learning interests, research projects, and their datasets. Then we designed the workshop content according to their interests and skill levels. After the workshop, we used the same set of spatial skill assessment questions to evaluate their learning, as well as ask open-ended questions about their future learning interests and comments. Figure 5 shows the average spatial skill evaluation results before and after an Introduction to GIS workshop. We asked twelve questions in the evaluation, with scores from 1 to 5 indicating their confidence of using spatial information. The questions were 
designed to measure students' spatial thinking skills for both map reading and GIS technology. The results showed that the students' spatial skills greatly improved after a three-hour workshop with the combination of instruction and hands-on exercises.

In addition to these efforts, our library is also collaborating with our College of Liberal Arts to offer a three-credit course for students in humanities and social science. The course content is built based on an intensive review of GIS course syllabi in different disciplines through Internet search, as well as our survey results and more detailed findings from our action research framework. The goal of this course is to offer the spatial, data, and tools skills to students at a more in-depth level, so that they can be confident to use the spatial information by themselves in their future research.

\subsection{Outreach Action and Observation}

To increase the awareness and visibility of GIS services in the library, over the past three years we took advantage of GIS Day celebration opportunities to promote geospatial concepts and our services. Although it is an event for GIS users in all disciplines, we tried to get more humanities and social science researchers involved in various ways. First, we invited faculty and graduate students from these disciplines to serve in the GIS Day planning committee and made sure that their interests and concerns were heard by the community. Second, we invited keynote speakers according to humanities and social science researchers' requests. These keynote speakers not only presented emerging GIS applications in these areas but also provided focus group discussions or workshops after their presentation to offer opportunities for further collaboration. Third, we encouraged and invited more faculty and graduate students from these disciplines to present and published these presentations in our institutional publication repository. Through the published pilot studies, more researchers in these disciplines began to learn of GIS possibilities in their related fields, as well as the availability of GIS support on campus. The active participation of humanities and social science scholars in GIS Day celebration showed a positive feedback of our efforts to promote spatial skills and GIS support in related disciplines.

\section{Discussion and Conclusion}

Through our research, practice, and observation, we have successfully identified the GIS research, learning, and outreach needs from the humanities and social science researchers and designed a relevant service model. Although GIS has a much larger user group in other disciplines on our campus, our designed services have greatly promoted GIS application in humanities and social science. By this time, the library's GIS staff have participated in many ongoing humanities and social science projects and provided many consultations for faculty and students. These services, designed specifically according to the community needs, have increased the interest of using spatial information among our humanities and social science faculty and graduate students. To accommodate the increased user demands, our library has just hired a new GIS staff member who will assist the GIS project management in multiple collaborations and help to organize general consultation information as online learning materials. To accommodate the increased data management needs, negotiations are underway with the university central IT to increase the libraries' capacity to host geospatial data.

Our study also indicated that the adapted action research framework can work efficiently in improving the library's GIS service for a specified user group. Since this framework is not limited by GIS service, it has a potential to be adopted in many other service areas in academic libraries. The information-gathering process not only helped us to hear from the community but also strengthened and extended our connections with the community. The data analysis and planning stages provided us with a thor- 
ough analysis of the community needs, balancing the expectations among different researchers and addressing the common pressing needs across disciplines. The action and observation stages allowed us to test our plans and collect feedback to improve our future practices.

We adapted the DCP toolkit as our primary information collection method. Although it was designed primarily as a tool to collect data service needs, we were able to use it for this study to collect researchers' overall library service expectations throughout their project lifecycle. It provides a set of balanced and objective questions to collect information about the nature of the research projects, external information requirements, learning needs, and data management demands, as well as other open-ended questions. We observed that, before the DCP was adopted in this study, our interviews with researchers were often driven by their personal interests or some specific unresolved issues that were significant around the time of the interview. With the DCP toolkit, we were able to hear the opinions in a more consistent and relevant way to help us improve the library's service. Our study also suggested that DCP can be successfully modified and adapted for very specific discipline and for very specific research groups.

The user expectations and service models we have built through this study are limited to our campus. Without a geography department, there is no general "Introduction to GIS" course and lack of a strong geography research approach across the campus. Although GIS has been taught and used in many research areas, such as agriculture and engineering, there were very limited resources for humanities and social science researchers to take advantage of the spatial information. Therefore, the library became the central unit for geospatial information resources and learning support for these disciplines. The service model in other universities will be very different from ours if there are different departmental settings, different courses offered, and different research collaboration models on campus.

In our future research, we will keep analyzing the information collected during our practice, as well as collecting new information to reflect the campus dynamic, to improve our existing GIS service model. To be more specific, in the research collaboration, we will generalize the collaboration models in different stages of the project development and design more general data services for a broader group of users. In the learning support, we will keep identifying the key elements in learning spatial information and provide the learning modules more relevant to the humanities and social science researchers. Finally, in the outreach activities, we will follow up the built connections and opportunities to promote spatial information awareness.

\section{Notes}

1. Camila Gabaldón and John Repplinger, "GIS and the Academic Library: A Survey of Libraries Offering GIS Services in Two Consortia," Issues in Science and Technology Librarianship 48 (2006): 1-8, available online at www.istl.org/06-fall/refereed.html [accessed 12 April 2015]; Bradley Wade Bishop, Adrienne W. Cadle, and Tony H. Grubesic, "Job Analysis of Emerging Information Professions: A Survey Validation of Core Competencies to Inform Curricula" Library Quarterly: Information, Community, Policy 85, no. 1 (2015): 64-84.

2. ACRL, "Top Trends in Academic Libraries," College \& Research Libraries 75, no. 6 (2014): 294-302.

3. The Spatial Turn: Interdisciplinary Perspectives, eds. Barney Warf and Santa Arias (New York, N.Y.: Routledge, 2008); Spatial Humanities: GIS and the Future of Humanities Scholarship, eds. David J. Bodenhamer, John Corrigan, and Trevor M. Harris (Bloomington: Indiana University Press, 2010), available online at http://site.ebrary.com/lib/purdue/reader.action?docID=10767195\&ppg=20 [accessed 4 May 2015].

4. Spatial Humanities, eds. Bodenhamer, Corrigan, and Harris.

5. S. Griffiths, "GIS and Research into Historical 'Spaces of Practice': Overcoming the Epistemological Barriers," in History and GIS: Epistemologies, Considerations and Reflections, eds. A. 
von Lunen and C. Travis (London: Springer, 2013), 153-71; Deep Maps and Spatial Narratives, eds. David J. Bodenhamer, John Corrigan, and Trevor M. Harris (Bloomington: Indiana University Press, 2015).

6. Julie Sweetkind, Mary Lynette Larsgaard, and Tracey Erwin, "Digital Preservation of Geospatial Data," Library Trends 55, no. 2 (2006): 304-14, available online at http://muse.jhu.edu/ content/crossref/journals/library_trends/v055/55.2sweetkind-singer.html [accessed 28 December 2014]; Gregory H. March, "Surveying Campus GIS and GPS Users to Determine Role and Level of Library Services," Journal of Map \& Geography Libraries 7, no. 2 (2011): 154-83, available online at www.tandfonline.com/doi/abs/10.1080/15420353.2011.566838 [accessed 15 April 2015].

7. Lisa T. Abbott and Carolyn D. Argentati, "GIS: A New Component of Public Services," Journal of Academic Librarianship 21, no. 4 (1995): 251-56.

8. Gabaldón and Repplinger, "GIS and the Academic Library."

9. Nancy M. Cline and Prudence S. Adler, "GIS and Research Libraries: One Perspective," Information Technology and Libraries 14, no. 2 (1995): 111-15.

10. Kathleen W. Weessies and Daniel S. Dotson, "Mapping for the Masses: GIS Lite and Online Mapping Tools in Academic Libraries," Information Technology and Libraries 32, no. 1 (2013): 23-35; Ningning Kong, Tao Zhang, and Ilana Stonebraker, "Evaluation of Web GIS Functionality in Academic Libraries," Applied Geography, available online at http://linkinghub.elsevier.com/ retrieve/pii/S0143622814002720 [accessed 28 December 2014].

11. Julie Sweetkind-Singer and Williams Meredith, "Supporting the Information Needs of Geographic Information Systems (GIS) Users in an Academic Library," Science \& Technology Libraries 21, no. 3/4 (2001): 175-90.

12. Sweetkind-Singer and Meredith, "Supporting the Information Needs"; Eva Dodsworth, "Indirect Outreach in a GIS Environment: Reflections on a Map Library's Approach to Promoting GIS Services to Non-GIS Users," Journal of Library Innovation 1, no. 1 (2010): 24-34.

13. Abbott and Argentati, "GIS: A New Component of Public Services."

14. Dodsworth, "Indirect Outreach in a GIS Environment."

15. Steven Bell, Lorcan Dempsey, and Barbara Fister, New Roles for the Road Ahead: Essays Commissioned for ACRL's 75th Anniversary (Chicago: American Library Association, 2015); Ann G. Green and Myron P. Gutmann, "Building Partnerships among Social Science Researchers, InstitutionBased Repositories and Domaijn Specific Data Archives," OCLC Systems \& Services International Digital Library Perspectives OCLC Systems \& Services: Library Perspectives 23, no. 1 (2007): 35-53.

16. D. Scott Brandt, "Librarians as Partners in E-Research," College \& Research Libraries 68, no. 6 (2007): 365-68; Ningning Kong, "Exploring Best Management Practices for Geospatial Data in Academic Libraries," Journal of Map \& Geography Libraries 11 (Sept. 2015): 207-25.

17. Sweetkind-Singer and Meredith, "Supporting the Information Needs"; Jeanine Scaramozzino et al., "Map Room to Data and GIS Services: Five University Libraries Evolving to Meet Campus Needs and Changing Technologies," Journal of Map \& Geography Libraries 10, no. 1 (2014): 6-47, available online at www.tandfonline.com/doi/abs/10.1080/15420353.2014.893943 [accessed 1 May 2015]; Dodsworth, "Indirect Outreach in a GIS Environment."

18. Katherine H. Weimer, Miriam Olivares, and Robin A. Bedenbaugh, "GIS Day and Web Promotion: Retrospective Analysis of U.S. ARL Libraries' Involvement," Journal of Map \& Geography Libraries 8, no. 1 (2012): 39-57; Scaramozzino et al., "Map Room to Data and GIS Services"; Rhonda Houser, "Building a Library GIS Service from the Ground Up," Library Trends 55, no. 2 (2006): 315-26, available online at http://muse.jhu.edu/content/crossref/journals/library_trends/ v055/55.2houser.html, doi:10.1353/lib.2006.0058.

19. Abbott and Argentati, "GIS: A New Component of Public Services"; Dodsworth, "Indirect Outreach in a GIS Environment."

20. Kathy Weimer, Paige Andrew, and Tracey Hughes, Map, GIS and Cataloging/Metadata Librarian Core Competencies (2008), available online at www.ala.org/magirt/sites/ala.org.magirt/ files/content/publicationsab/MAGERTCoreComp2008_rev2012.pdf [accessed 10 April 2015].

21. Jake Carlson and D. Scott Brandt, "Data Curation Profiles: Purpose and Use of the Profiles," Data Curation Profiles Toolkit (2010), available online at http://datacurationprofiles.org/ [accessed 26 June 2015].

22. Hilary Bradbury and Peter Reason, Handbook of Action Research: Participative Inquiry and Practice (London; Thousand Oaks, Calif.: SAGE, 2001); Martyn Denscombe, The Good Research Guide: For Small-Scale Social Research Projects (Columbus, Ohio: McGraw-Hill Education, 2014).

23. Kurt Lewin, "Action Research and Minority Problems," Journal of Social Issues 2, no. 4 (1946): $34-46$.

24. Bradbury and Reason, Handbook of Action Research; Richard Sagor, Guiding School Improvement with Action Research (Alexandria, VA.: Association for Supervision \& Curriculum Development, 2000); Ortrun Zuber-Skerritt, Action Research in Higher Education: Examples and Reflections (London: Kogan Page, 1992). 
25. Carlson and Brandt, "Data Curation Profiles."

26. Michael Witt, Jacob Carlson, D. Scott Brandt, and Melissa H. Cragin, "The International Journal of Digital Curation Constructing Data Curation Profiles," International Journal of Digital Curation 4, no. 3 (2009): 93-103.

27. Barbara DiCiccio-Bloom and Benjamin F. Crabtree, "The Qualitative Research Interview," Medical Education 40, no. 4 (2006): 314-21, doi:10.1111/j.1365-2929.2006.02418.x; Kathy Charmaz, Constructing Grounded Theory: A Practical Guide through Qualitative Analysis, 1st ed. (Thousand Oaks, Calif.: SAGE Publications Ltd., 2006).

28. Barney Glaser and Anselm Strauss, The Discovery of Grounded Theory (Chicago, IL: Aldine Transaction, 1967); Chiara Faggiolani, "Perceived Identity: Applying Grounded Theory in Libraries," JLIS.it 2, no. 1 (2011), available online at http://leo.cineca.it/index.php/jlis/article/view/4592 [accessed 6 July 2015].

29. A.J. Hutchison, L.H. Johnston, and J.D. Breckon, "Using QSR-NVivo to Facilitate the Development of a Grounded Theory Project: An Account of a Worked Example," International Journal of Social Research Methodology 13, no. 4 (2010): 283-302, available online at http://shura.shu. ac.uk/2565/, doi:10.1080/13645570902996301; J.D. Bringer, L.H. Johnston, and C.H. Brackenridge, “Using Computer-Assisted Qualitative Data Analysis Software to Develop a Grounded Theory Project," Field Methods 18, no. 3 (2006): 245-66, doi:10.1177/1525822X06287602.

30. Abbott and Argentati, "GIS: A New Component of Public Services"; Dodsworth, "Indirect Outreach in a GIS Environment."

31. Jongwon Lee and Robert Bednarz, "Components of Spatial Thinking: Evidence from a Spatial Thinking Ability Test." Journal of Geography 111 no. 1 (2012): 15-26. doi:10.1080/00221341 .2011 .583262 . 